\title{
STARBUCKS INTERNATIONAL ENTERS KUWAIT
}

\author{
By: Dianne H.B. Welsh, Ph.D, Peter Raven, Ph.D. ${ }^{1}$, Nasser Al-Mutair, and Peter V. Raven \\ Raven, P., Welsh, D.H.B., \& Al-Mutair, N. (1998). Starbucks International enters Kuwait. \\ Journal of Consumer Marketing, 15(2), 191-197.
}

Made available courtesy of EMERALD GROUP: http://www.emeraldinsight.com

***Note: Figures may be missing from this format of the document

\begin{abstract}
:
This case describes the situation surrounding the entrance of Starbucks International Coffee into the Kuwait marketplace. It requires students to consider relevant small business and entrepreneurship issues in determining an appropriate response. These issues include: international joint ventures, culture, gender issues, marketing channels, and cross-cultural management issues.
\end{abstract}

\section{Article: \\ INTRODUCTION}

After a long and tiring flight from Seattle to Kuwait via London, the Kuwaiti Airlines jetliner finally lands and Mr. Howard Behar mentally prepares to meet with Mr. Nasser Al-Mutair. This meeting has been anxiously anticipated by both parties.

Nasser is a young businessman recently graduated with a degree in marketing from a regional university in the State of Washington. This is where he became familiar with Starbucks Coffee and learned of Mr. Behar, the President of Starbucks International Coffee Company.

Nasser had so enjoyed the Starbucks specialty coffees as a student and had observed how many Americans and other international students also loved to drink this popular coffee. Knowing the fondness that Arab people have for coffee, Nasser thought that a specialty coffee shop might be successful in Kuwait, which has seen an increasing number of Americans and other foreigners since the Gulf War. As a marketing student, however, Nasser realized the importance of planning, obtaining information, and getting expert opinions. He had personally invited Mr. Behar to visit with him in Kuwait City, so that Mr. Behar could see the sites Nasser had selected and to discuss this possible expansion in person. While the deal was far from complete, Nasser was very confident that his plan would succeed, but was anxious to hear Mr. Behar's opinion.

\footnotetext{
${ }^{1}$ Professor Raven's teaching interests include Internet marketing, entrepreneurship, international marketing, and marketing research. He taught at Washington State University and at Eastern Washington University before coming to Seattle University as an associate professor. His research interests include export marketing, cross-cultural consumer behavior, international marketing management, global marketing ethics, global e-commerce, and global Internet marketing. He has published in a number of international scholarly journals, including the Journal of International Marketing, Journal of Consumer Marketing, Journal of Marketing Channels, Franchising Research: An International Journal, Journal of Global Marketing, Journal of Advertising Research, and others.
} 
In fact, Nasser had to persuade not only Mr. Behar that his idea was sound, but also his uncle, Abdul Al-Mutair. Abdul Al-Mutair had long been a prominent financial leader in Kuwait, primarily involved with importing consumer products and trading. He had recently become interested in the service industry. With the increasing number of foreigners living in Kuwait, even for relatively short periods of time, he realized that traditional restaurants were inadequate to meet their desires. After Nasser had returned from the United States with his newly acquired degree, he and his uncle had long talks about what they might do together. Nasser had some interesting ideas and might be a good person to explore new ventures. Abdul Al-Mutair was considering financing Nasser's venture if it seemed feasible and profitable.

Mr. Behar was anxious to meet with Nasser and also very curious. He had never been to the Middle East and was uncertain what he would find there. He had had little time to learn about the country or culture, but he had certainly heard about Kuwait and had seen pictures of it during the Gulf War. In addition, Mr. Behar was very interested in expanding his international operations. His main concerns included the image of Starbucks International and profitability. Although curious, he had a number of misgivings about expansion into the Middle East.

As Mr. Behar stepped out of the plane, Nasser met him and escorted him rapidly through customs and the unfamiliar airport. After a brief tour of the city in a chauffeured Mercedes limousine, they arrived at a small restaurant near the center of town for some refreshments. Behar was taken with the unique beauty of Kuwait City.

The restaurant was a rather small, nondescript locale. They began to talk about the trip and other small talk, when Mr. Behar suddenly said, "I really would like to try some of your traditional coffee." Nasser said, "Yes, we have excellent Arabian coffee. This restaurant also serves French Press and Turkish coffees. You should try some Turkish coffee. It will be different from coffees you've had in other places." Mr. Behar said, "Yes. It's been a long time since I have had Turkish coffee." Nasser ordered some for both of them.

While waiting for his coffee, Mr. Behar was able to observe the restaurant which reminded him of some of the restaurants in Italy where Mr. Howard Schultz, President of Starbucks, first got the idea for Starbucks coffee shops. The coffee was soon served. He had forgotten how good this coffee was and how it resembled straight espresso in texture and strength. He thought to himself, this is either a very good sign for our coffee-shops--the Kuwaitis already like richer, stronger coffee, or it could be a bad sign in that they might not want another choice. He listened attentively as Nasser spoke "We love our Turkish and Arab coffees, but I know many of the Kuwaitis who have spent time in the United States, especially the Pacific Northwest, miss their espressos and would like a variety of coffee choices." Mr. Behar and Nasser continued talking for some time. However, they realized that a decision would have to be made quickly, as Mr. Behar had to be in Europe the next day, where he was opening five new stores.

\section{KUWAIT AND THE MIDDLE EAST}

\section{Geography}

Kuwait is located in the Northeast corner of the Arabian Gulf. To the south and southeast it shares a border with Saudi Arabia. To the north and west is Iraq. The distance between the northern southern borders is about 200 kilometers (124 miles) and between the eastern and 
western borders about 170 kilometers (106 miles). The total area of the State of Kuwait is 17,818 square kilometers (6,969 miles).

Most of Kuwait's mainland is flat, sandy desert that slopes gradually to the sea. The Kuwait mainland has no mountains, rivers or other natural features. Historically, it was a crossing for nomadic tribes and caravans.

The weather is characterized by long, hot, dry summers and short, warm winters. Sometimes there is quite a bit of rain. In the summer, there are many dust storms and the humidity increases dramatically.

There has always been a strong connection between Kuwait and the sea. This relationship has shaped the character of the Kuwaitis. The main source of income came from the sea in earlier times, and the sea is still a great source of pride and activity. Many people, including young people, still spend much time fishing. In the evenings, many people can be found on the beaches.

\section{Population}

The total population of Kuwait is about 2.1 million. If the current rate of growth remains the same, it will be approximately 3 million by the year 2000. A large percentage of the population are non-Kuwaitis. Since the Gulf War, the country's demographic patterns have been changing. Foreign nationals make up about $55 \%$ of Kuwait's population. The largest group are from Pakistan and India. There are about 6,200 Americans in Kuwait, mostly military personnel. They compose the largest Western community.

\section{Economy}

In the last five to ten years, an increasing number of companies have realized the opportunities that exist in the Persian Gulf markets. This region has often been described as a area in which there are many profitable opportunities for the following reasons:

- high purchasing power;

- heavy reliance on imported products;

- massive consumer demand due to the fast-growing population.

Thus, the economic profile of the region suggests increasing opportunities. Although analysts expect that the Middle East will become an extremely important area for business, part of the growth will depend upon peace in the Middle East. For example, Israel has not been able to fully participate in the Middle East market since Arab countries have traditionally not done business with Israel. Whether the Middle East becomes a unified market depends largely on future political agreements.

Many people believe that tourism will continue to grow in the Middle East. Tourism has not been highly developed. Although tourism has continued to increase at an average of $6.5 \%$ per year since 1983, most of the tourists to the Middle East are also from the Middle East. In 1992, for example, just $27 \%$ of the tourists were from the Americas or Europe. The most popular tourist place by far is Egypt, with Israel and Bahrain the next most popular places for people to visit. 
The Middle East is attracting the attention of such developers as Howard Johnson's Motor Inns, which has just built a 115-room Hotel in Dubai, United Arab Emirates (UAE). The chain is planning to do more building in the Middle East in the next few years. Also, in the last several years, many fast-food franchised restaurants have opened in Persian Gulf countries. Some examples include Kentucky Fried Chicken, McDonald's, Baskin-Robbins, Hardee's, Wendy's, Popeye's Fried Chicken, and so forth. Entry into Kuwait might facilitate entry into some of these other countries in the Middle East.

\section{STRATEGIC ALLIANCES}

One popular way to become involved in business in the U.S. is through franchising. While franchises are also a popular way of entering some international markets, strategic alliances are increasingly utilized. In fact, strategic alliances are often required by some countries, rather than other modes of entry, as they involve local firms directly in the business. U.S. commercial analysts have conducted a study on the Egyptian and Kuwaiti markets to discover opportunities for American companies. Their findings suggest that these markets would grow to an estimated $\$ 51$ million in 1992, and are expected to increase from 10 to 20 percent a year on average over the following three years. Revenues from foreign retail stores in Kuwait totaled about $\$ 8$ million in 1993 and are expected to rise at an average annual rate of 25 percent through 1996.

Many of Kuwait's residents have large disposable incomes and are likely to buy American products. While most U.S. firms currently operating are fast-food restaurants, other opportunities are developing. Kuwaitis are eager to meet with foreign companies. One characteristic of the Kuwaiti market that U.S. businesses should be aware of is that Kuwaiti tastes tend to change, switching from traditional to what is new and trendy. Kuwaitis travel frequently and are aware of the latest fashions in Europe and the U.S. As a result, some businesses go out of vogue after about 10 years on average. While its economy is still recovering from the war, average annual growth for all franchise areas is expected to reach $25 \%$ through 1996, but could reach as high as $60 \%$ for some franchises.

As indicated earlier, the most common type of franchise is fast-food, but there are opportunities in other areas, as well. Based on a recent market research study, some other areas of potential for franchisers in Kuwait include:

- Automotive Repair and Service

- Recreation. Travel, sports hobbies.

- Beauty and Health Aids

- Carpet Dyeing and Cleaning.

- Children's Entertainment Services and educational products and services

- Printing and Copying centers

- Coffee Shops

- Florist Shops

Although the competition in the Kuwaiti market is tough, American companies could do well because a large number of Kuwaitis have studied in the United States and are familiar with U.S. firms. Despite this, Japan has passed the U.S. in the past year as the leading exporter to Kuwait. 
Franchises and strategic alliances mainly compete in two ways: through advertising campaigns in the local media and local TV stations; or through promotions, offering free meals for a certain number of purchases or free children's gifts. Kuwait has four main shopping areas, located in Salmiya, Kuwait City Center, Hawalli, and Fahaheel.

Kuwait has a free market with few restrictions on imports. Customs duties are 4 percent across the board. Standards and label requirements apply to some imports. One study advises foreign companies to visit the country to become familiar with the size of the market and its characteristics. In general, to conduct business in Kuwait, every foreign firm should have a local agent, distributor, or representative.

\section{The Coffee Shop Market}

In the US, there are hundreds of coffee shops, drive-ins, and restaurants that offer specialty coffees. One of the most successful brands of coffee has been Starbucks. Its success in the US may translate to success in Kuwait, if everything is done correctly. Many people in Kuwait drink coffee on a regular basis. In fact, it is considered a high act of hospitality to serve coffee to guests. One of the most popular coffee drinks in Kuwait is Turkish coffee, which is similar to straight espresso coffee served in the Pacific Northwest.

\section{Starbucks Coffee}

Starbucks Coffee is a chain of coffee specialty stores that began in 1971 as one small shop in Seattle's Pike Place Market. In the past nine years, it has gone through rapid growth, expanding from 11 stores in 1987 to a total of 500 today.

Mr. Howard Schultz had been a buyer for Starbucks Coffee since the early 1980s. On a coffeebuying trip to Milan, Italy, he noticed that crowds of people gathered each day in coffee bars to drink their specialty coffees. Schultz wondered if the same thing could happen elsewhere. Back in Seattle, he attempted to persuade his bosses to try the coffee bar idea and go beyond just selling coffee beans to restaurants. They refused. Schultz raised \$1.7 million dollars and opened his own cafe in downtown Seattle. The first coffee he served was Starbucks. In less than a year, he had opened two more stores. Subsequently, he bought out Starbucks from his former employers for $\$ 4$ million.

Specialty coffees have slowly taken business away from the traditional canned coffees. The high-quality coffee bean industry created $\$ 717$ million in sales in 1990 , with a 13.5 percent share of the coffee market. By 1991, the penetration was even deeper. Gourmet sales had reached $\$ 800$ million and their market share rose to 17.7 percent. In the meantime, coffee shops grew at a rapid rate. By 1992, Seattle had 150 coffee bars.

Starbucks' mission statement reads, "To establish Starbucks as the premier purveyor of the finest coffee in the world while maintaining our uncompromising principles as we grow." Some of the principles of the company are treating everyone with respect and dignity, buying the best available coffees, developing loyal customers, contributing to the environment, and making a profit. 
While this hardly makes the company unique, what does make the company special is that it seems to understand the connection between delivering a great cup of coffee and treating their employees with respect. One training manager suggests that the quality of everything comes down to the employee experience. The company's culture is built on very strict standards for how coffee should be prepared and delivered, combined with an empowering attitude toward the employees who deliver the coffee to the customers.

Starbucks is opening 150 stores a year in new markets across the United States. Almost 2 million Americans visit Starbucks coffee shops each week. During 1995, it planned to open 200 new stores and to expand overseas. However, growth is beginning to slow in the American market, due to intense competition. Also, higher coffee prices have hurt the domestic industry. In 1994, Starbucks earned approximately $\$ 13$ million. International expansion is a strategic plan and occurs through Starbucks International, of which Mr. Howard Behar is President. Starbucks International policy requires strategic alliances in its development of international markets.

Many people believe that Starbucks is the model for growth in a small company. When sales start to take off, many small companies have problems and begin to fail. But it is said that Schultz has placed top quality and experienced managers from larger chains into Starbucks and has invested heavily in personnel, information systems, and facilities. The company is constantly checking its image, its interior design, and locations. Starbucks believes that site selection is a key to success. The real estate division begins working up to nine months before a store is opened. They collect large amounts of information on the income, education, and coffeebuying habits in the new market.

Schultz feels the market is far from saturated. Slow growth in established stores is not a concern. In September of 1994, Starbucks bought its first acquisition, The Coffee Connection, Inc. of Boston, Massachusetts. In 1995, Starbucks planned to team up with foreign partners to open stores in Europe and Asia. However, it is possible that the Starbucks "chic" may not be popular overseas. Starbucks has a joint-venture with Pepsi to bottle its iced coffees.

To summarize, Starbucks has a strong reputation for quality because of the following:

- The company goes to extreme lengths to buy the very finest arabica coffees available on world markets, regardless of price.

- The company's freshness and quality are legendary. Beans that are held in bins for more than a week are donated to charity.

- Every piece of coffee-brewing equipment that is sold has been tested and evaluated.

- Each Starbucks employee is extensively trained to ensure that customers receive knowledgeable service.

During the last 20 years, consumer interest in fine coffees has increased greatly. All over the country, people who used to be content with canned commercial blends are now searching for fresher, more flavorful alternatives. Whole bean coffee is now sold in kitchen shops, delicatessens, grocery stores and supermarkets. Coffee lovers have learned, however, that buying whole beans does not guarantee great coffee. The freshness standards set at Starbucks in 
1971 are still being used today. Over the years, Starbucks has grown to become one of the largest purchasers of high-quality arabica coffees in the United States. They also have in-store coffee bars that have set the international standards for espresso, cappuccino and drip coffee.

Most of the specialty drinks use espresso, which is a brewing method, a blend of beans, a roast color, and a beverage. Espresso is a rapid method of brewing which uses pressure, not gravity to brew. Starbucks Espresso is a unique blend of Central American and Indonesian coffees which yields a thick, caramel-sweet, and highly aromatic espresso.

\section{A Decision}

As Nasser takes Mr. Behar to his hotel for the evening, each has many thoughts and ideas to consider. Tomorrow promises to be a pivotal day, as a meeting is scheduled with Nasser's uncle, Abdul Al-Mutair. Nasser knows that Abdul will ask some very penetrating questions and will expect direct, well thought-out answers. Howard Behar also has mixed feelings and is anxious to get Mr. Abdul Al-Mutair's perspective. He suspects that, with the right contract, a Kuwaiti operation would be very successful. Tomorrow will be Mr. Behar's last day in Kuwait, as he must leave in the late afternoon for his flight to Frankfurt.

\section{QUESTIONS}

1. What questions should Mr. Behar ask Mr. Abdul Al-Mutair tomorrow?

2. What questions would you anticipate Mr. Abdul Al-Mutair asking Behar? Nasser?

3. Should Nasser and his uncle invest in a Starbucks International joint venture in Kuwait? Why or Why not?

4. What further information would you like to obtain before making the decision for Nasser and his uncle? Where and how will you obtain this information?

5. Assuming the decision is to proceed, what information is needed to select a location? How will this information be obtained? Why is it important?

6. What specifics should Behar insist on in a contract with the Al-Mutairs? Why?

7. Assuming all parties agree to a joint venture, how should the coffee shop differ from those in the U.S. in order to satisfy the needs of Kuwaitis?

8. What type of marketing strategy should be adopted?

\section{TEACHING GUIDE}

This case is fictitious, but was developed from personal experiences and information. It incorporates a potentially real situation and business opportunity. This case has a number of possible uses. The case can be used to explore the introduction of an innovation into a foreign country. While students might be familiar with the product, Starbucks Coffee, and the mode of distribution through coffee houses, the context and culture within which the case takes place is unique. The case can also be used to simulate expansion into a foreign market through strategic alliances. Several decisions must be made with less than complete information. This is frequently the case in foreign markets. Thus, critical analysis must occur with very limited information.

The case can best be used in international marketing and management courses, or in a marketing channels course. It would make an excellent supplement to a marketing management / strategy course, in that it brings a great deal of uncertainty into the decision making process. 
Instructors might suggest that students supplement the case with information obtained from other sources. In fact, the case scenario is good background for information that can be obtained from the Internet. For example, students might be assigned individually, or in groups, to determine the feasibility of such an endeavor, target market share, potential profit, competition, legal concerns, and other areas of interest.

Answers to End of Case Questions:

1. What questions should Mr. Behar ask Mr. Abdul Al-Mutair tomorrow?

Possible questions include: What potential does Mr. Al-Mutair see for expansion into other cities in Kuwait and the Persian Gulf? What financial arrangements would be required? What should a coffee shop serve? To whom should they target?

2. What questions would you anticipate Mr. Abdul Al-Mutair asking Behar? Nasser?

To Behar: Why are you interested in Kuwait? What experience have you had in entering new markets, especially foreign markets? What benefits will Kuwaitis derive from this venture? To Nasser: Have you considered the amount of effort required to make this project work? Are willing and able to make this venture work?

3. Should Nasser and his uncle invest in a Starbucks franchise in Kuwait? Why or Why not?

Students will have different responses to this question, but in any case, should develop sufficient justification for their positions. Starbucks International could enter the Kuwaiti market. The population has a large discretionary income. Serving and drinking coffee is an important social custom, so the product would be easily accepted. The Kuwaitis already have a taste for strongly flavored coffees. Plus, Kuwaitis like American products, and many have been exposed not only to European style coffee shops, but American as well.

4. What further information would you like to obtain before making the decision for Nasser and his uncle? Where and how will you obtain this information?

Critical information needed includes: Potential market size (i.e., number of coffee drinkers, amount spent in coffee houses); Profile of target market (demographics, psychographics, social class, income, etc.); Possible locations; and others.

Other information: Potential markets outside Kuwait City and in other Persian Gulf countries; Potential competitors; Other uses of resources; etc.

5. Assuming the decision is to proceed, what information is needed to select a location? How will this information be obtained? Why is it important?

Site location is critical for Starbucks International, as for any retail operation. The right location, along with other factors, will help assure its success. Starbucks International considers site location especially important, judging by its use of a special department for this purpose. 
Specific criteria for site selection have obviously been developed by Starbucks International. While students may not have access to the specifics, such factors as foot traffic, vehicle traffic, proximity to other shopping outlets, etc. should be considered. Obtaining this information may be more problematic, but secondary sources may be available or it might be necessary to conduct primary research at several potential sites.

6. What specifics should Behar insist on in a contract with the Al-Mutairs? Why?

Students will have various answers, but should include something about repatriation of profits, fees, and currency considerations, including foreign exchange rates, inflation, government controls, etc. Other specifics should include method of conflict resolution, legal jurisdiction (probably Kuwait), expansion policy, quality assurance program, authority and responsibilities of both parties.

7. Assuming all parties agree to a joint venture, how should the coffee shop differ from those in the U.S. in order to satisfy the needs of Kuwaitis?

Students can be quite innovative in answering this question. Cultural differences might influence shop design. For example, the shop should be much larger than is usually found in the U.S. There should be two different sections, one where smoking can take place. This might be a place where young men like to gather, as is often the case in restaurants in the Middle East. Then another section where women or families could gather and be comfortable. The Kuwaiti society has become much more open as far as single men and women socializing, but there should be the option of choosing a more separate location for men. The "American" aspects of the shop could be emphasized. The shop could be very different from competitors to emphasize differentiation. The shop may have two sections, a coffee-drinking area and a coffee bean/coffee equipment purchasing area.

8. What type of marketing strategy should be adopted?

Students should be encouraged to be innovative and imaginative in answering this question. A positioning strategy emphasizing exclusivity, for example, should incorporate consistent pricing and promotional strategies, while shop design could emphasize "high-class" Americana. Product offerings should probably be relatively limited in the beginning, until Kuwaiti tastes and preferences are ascertained. However, there probably should be some strategy for introduction of new products. In any case, there should be justification for any strategy selected. 


\section{REFERENCES}

Anonymous (1994). Franchising Opportunities: Fast Food and More, Part I. Middle East Executive Reports, 17, No. 2, February.

Anonymous (1994). Franchising Opportunities, Part II. Middle East Executive Reports, 17, No. 3, March.

Dravo, Ed (1994). Java Jive. Financial World, 94, No. 17, August 16, 78.

Filipczak, Bob( 1995). Trained by Starbucks, and Born to be Wired. Training, June, 73.

Leonidaou, Leonidas, C. (1995). The Saudi Distribution System: Structure, Operation and Behavior. Marketing Intelligence and Planning, 13, No. 11, 27.

Oleck, Joan (1993). When Worlds Collide. Restaurant Business, 92, No. 10, July 1, 48.

Scarpa, James (1995). Java Nation. Restaurant Business Magazine, 94, No. 13, September 1, 9697.

Wang, Grace (1995). A Natural Extension: A new name along with a plan for hotels spanning the globe. Lodging Hospitality, 51, No. 10, November, 33.

\section{Starbucks Enters Kuwait Case Epilogue and Update 2001}

(March 2001)

Since this case was written (1996) a number of changes have occurred. Starbucks did enter the Kuwait market and now has six stores in Kuwait. Global expansion has also increased with 3881 stores now open, 643 of which are outside North America. (Business Wire, February 1, 2001).

Starbucks Coffee International opened its first store in Kuwait on February 9, 1999, at the Souk Sharq, Gulf Road, Sharq. It is operated in partnership with M.H. Alshaya Co. W.L.L., with whom Starbucks Coffee International has a multi-jurisdictional licensing arrangement (Business Wire, May 31, 2000). Kuwait serves as the gateway into the rest of the Middle East countries as, together, the two companies already have or plan to open stores in Saudi Arabia, Oman, Bahrain, United Arab Emirates, Qatar and Lebanon ("Starbucks Opens Another Store Abroad - In Kuwait," Seattle Post - Intelligencer; Seattle, WA, February 15, 1999).

As quoted at the time,

Starbucks Coffee International and M.H. Alshaya Co. W.L.L. announced today plans to expand into the Gulf Cooperation Council (GCC) countries with the opening of the first Starbucks retail location in Kuwait at the Souk Sharq, Gulf Road, Sharq. "We are excited with our opening in Kuwait as it will serve as our gateway into the GCC countries. It will also create wonderful expansion opportunities for us to the rest of the Middle East," said Howard Behar, President of Starbucks Coffee International. "Starbucks is also 
proud to have found a great partner who not only has expertise in the region's marketplace, but shares our business principles and people values."

"The people of Kuwait will wholeheartedly embrace the unique specialty coffee experience of Starbucks as the company offers the best of class in everything it does," said Mr. Mohammed Alshaya, CEO Retail Division of M.H. Alshaya Co. W.L.L. "Starbucks will be a success in Kuwait as it stands for uncompromising commitment to people, quality coffee and innovative products."

M.H. Alshaya Co. W.L.L. is one of the largest and most successful operators of leading global retail brands in the Middle East. It is a family-owned business recognized for its leadership role in real estate development, hotel management, warehousing, car dealerships, food services and retail operations. ("Starbucks Coffee Company Opens First Store in Kuwait; Expansion into the GCC Countries to Follow,” Business Wire, February 9, 1999).

\section{About M. H. Alshaya Co. W.L.L}

Alshaya has become a byword for trading and commerce excellence in the Arabian Gulf. Since its foundation in 1890, they have become a major player within a variety of sectors; initially in the Kingdom of Saudi Arabia and Kuwait and, more recently, throughout the Middle East. Today, they have over 4,000 employees; of these, more than 2,100 work within the retail division (Alshaya Home Page, accessed 3/18/2001, http://www.alshaya.com/leader.htm).

Alshaya Retail operates more than 20 international retail brands throughout the Middle East - the Kingdom of Saudi Arabia, Kuwait, the United Arab Emirates, Bahrain, Qatar, Oman and Lebanon. These include many of the world's leading clothing, health \& beauty, fashion and restaurant names, all carefully chosen to bring the highest brand and label quality to the region's premier retail locations. Alshaya Retail represents a number of lines, including The Body Shop, Mothercare, Liz Claiborne, Laura Ashley, Clinique, Esteé Lauder, Starbucks and currently operates over 200 stores in seven countries.

Kuwait and Saudi Arabia each has over 60 outlets, with more than 30 in the UAE and a significant presence in Bahrain, Qatar, Oman and Lebanon. They are also looking at retail opportunities in Egypt, Jordan and Syria.

Starbucks Coffee International, and M.H. Alshaya Co. W.L.L., celebrated the opening of the first Starbucks retail store in Qatar on August 01, 2000. Qatar represents the fourth country in the Middle East that Starbucks has entered. Following the signing of a multi-jurisdictional licensing agreement with M.H. Alshaya Co. W.L.L. of Kuwait, the first Starbucks store was opened in Kuwait on February 9, 1999. In Lebanon, the first Starbucks store was opened in Beirut on November 29, 1999, while Dubai celebrated the opening of the first Starbucks store on May 31, 2000. "The Middle East is an exciting market for Starbucks," said Peter Malsen, president of Starbucks Coffee International. "In the Middle East market, our partner, M.H. Alshaya Co. W.L.L., has been instrumental in the phenomenal reception we have received in Kuwait, Lebanon and Dubai. We plan to expand into Saudi Arabia and Bahrain by the end of the year." (Alshaya Company News, http://www.alshaya.com/news.htm, accessed 3/18/2001). 
"The opening of our first retail store in Qatar is a celebration of Starbucks uncompromising commitment to people, quality coffee and innovative products," said Mr. Mohammed Alshaya, CEO of M.H. Alshaya Co. W.L.L. "The coffee culture in Qatar will be greatly invigorated with Starbucks entry as the market leader in the country." M.H. Alshaya Co. W.L.L. is one of the largest and most successful operators of leading global retail brands in the Middle East. Its affiliate company, Dareen International Co. (Qatar) W.L.L., will operate Starbucks stores in Qatar (Alshaya Company News, http://www.alshaya.com/news.htm, accessed 3/18/2001).

Starbucks Coffee France EURL, a wholly owned subsidiary of Starbucks Coffee Internaltional, and Dareen International Co. L.L.C., an affiliate company of M.H. Alshaya Co. W.L.L., opened the first Starbucks retail store in Dubai City, Dubai. Also, through a multi-jurisdictional licensing agreement with M.H. Alshaya Co. W.L.L., Starbucks has stores in Kuwait and Lebanon (Cuevas, Li and Darek Johnson, "Methods to Build International Business: Starbucks Demonstrates Successful Expansion Methods," Signs of the Times, http://www.signweb.com/management/cont/management0900.html, accessed 3/18/2001).

Starbucks Coffee International is a wholly owned subsidiary of Starbucks Coffee Company, the leading retailer, roaster and brand of specialty coffee in the world. In addition to the Republic of Korea, Starbucks has retail locations in Japan, Hawaii, Singapore, the Philippines, Taiwan, Thailand, the United Kingdom, New Zealand, Malaysia, Beijing, Kuwait, Lebanon, the United Arab Emirates (Dubai), Qatar, Hong Kong, Shanghai, Australia, Saudi Arabia and Bahrain. 